\title{
Molar Heat Capacity of 1,2-Cyclohexanediol Isomers From (173 to 428) K
}

\author{
Teresa M. R. Maria* and M. Ermelinda S. Eusébio \\ Departamento de Química, Universidade de Coimbra, 3004-535 Coimbra, Portugal
}

Heat capacities of cis-1,2-cyclohexanediol and trans-1,2-cyclohexanediol enantiomers have been determined in the solid state in the temperature range $T=(173$ to 368$) \mathrm{K}$ for the cis-isomer and $T=(173$ to 373$) \mathrm{K}$ in the case of the trans-isomer and in the liquid state at temperatures up to $428 \mathrm{~K}$. Measurements were carried out by differential scanning calorimetry using the enthalpic method. For the cis-isomer, the results show that, before the liquid state is reached, a highly disordered phase is formed. The trans-enantiomers show only a one-step fusion process. The values obtained for the solids are quite well predicted by Goodman's power law group contribution method, except for the lower temperatures. The Rûžička method was tested for the prediction of liquid state heat capacity values giving results (15 to 20) \% lower than the experimental values.

\section{Introduction}

In the present work, the heat capacity of trans-1,2-cyclohexanediol enantiomers and of $c i s-1,2$-cyclohexanediol in the solid and liquid states are reported at temperatures ranging from $T$ $=(173$ to 428$) \mathrm{K}$ using differential scanning calorimetry. Furthermore, a comparison of the experimental data with values calculated using the group contribution methods developed by Goodman et al. ${ }^{1}$ for the solid state and by Rûžička et al. ${ }^{2,3}$ for the liquid state is made.

The isomers of 1,2-cyclohexanediol are used in the preparation of many high-value compounds, ranging from keto alcohols to polymers. ${ }^{4-9}$ In addition, optically active 1,2-diols play an important role as chiral auxiliaries in the syntheses of enantiomerically pure compounds ${ }^{10}$ an increasingly attractive research field for the development of modern drugs and agrochemicals. ${ }^{11-13}$

The molar heat capacity is a fundamental thermodynamic property. In fact, the knowledge of heat capacities at various temperatures is essential for the calculation of the thermodynamic properties, such as enthalpy, entropy, and Gibbs energy, as a function of temperature as well as to assess the effect of temperature on reaction and phase equilibria. Changes in heat capacity are also an indicator of phase transitions and an important tool for understanding modifications in the structure of solids and liquids.

Besides obtaining precise heat capacity values for both 1,2cyclohexanediol isomers, there is another motivation for studying these systems. From previous work on the 1,2-cyclohexanediol isomers, ${ }^{14,15}$ the existence of a mesophase preceding fusion was evidenced for the cis-isomer, while for the transisomer a unique step fusion was observed. Heat capacity values may give a valuable contribution to the characterization of this mesophase.

\section{Experimental Section}

Materials. cis-1,2-Cyclohexanediol, mass fraction $x \geq 0.99$, was purchased from Aldrich and trans-1,2-cyclohexanediol enantiomers, mass fraction $x=0.99$, from Fluka Chemie.

* To whom correspondence should be addressed. E-mail: troseiro@ ci.uc.pt quierme@ ci.uc.pt. Phone: +351239 854472. Fax: +351239827703.

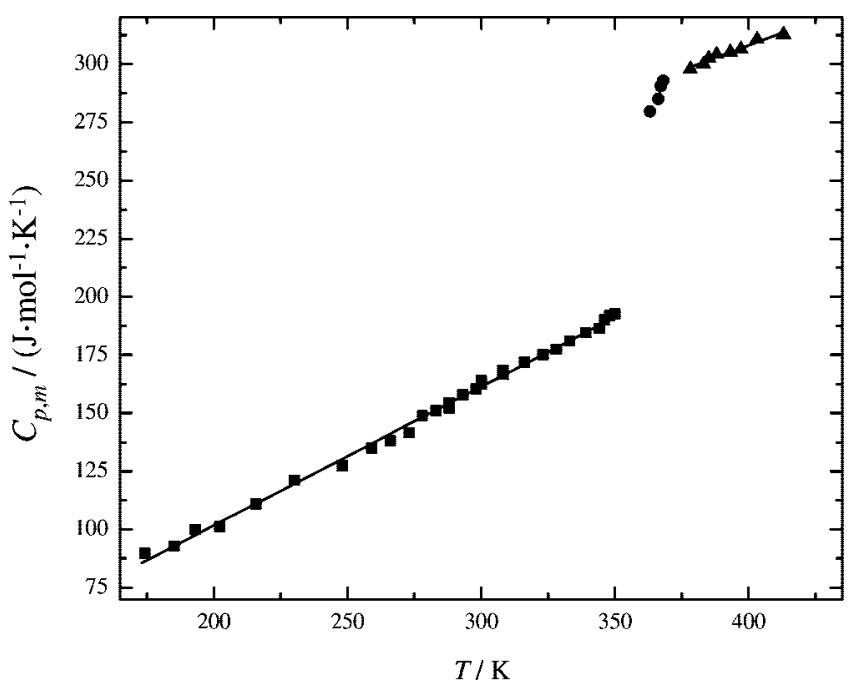

Figure 1. Molar heat capacity of the condensed phases of cis-1,2cyclohexanediol in the temperature range from $T=(173$ to 413$) \mathrm{K}$. $\mathbf{\square}$, crystal II; $\bullet$, crystal I; $\mathbf{\Lambda}$, liquid.

The compounds were purified by sublimation using the coldfinger technique $\left(T=353 \mathrm{~K}, p=10^{3} \mathrm{~Pa}\right.$, freezing fluid: cold water). The purity of the sublimed samples was determined by gas chromatography (column Supelco $\beta$-DCX, $d=0.25 \mathrm{~mm}, l=30 \mathrm{~m} ; T=373 \mathrm{~K}$; carrier gas: helium; flame ionization detector; $d$ and $l$ are the internal diameter and the length of the column, respectively) and was better than $99.9 \%$.

Apparatus. Measurements were carried out in the temperature range between $T=(173$ to 428$) \mathrm{K}$ using a PerkinElmer DSC7 (CCA7 cooling unit, $20 \mathrm{~mL} \cdot \mathrm{min}^{-1} \mathrm{~N}_{2}$ purge) and a Pyris 1 (Cryofill cooling unit, $20 \mathrm{~mL} \cdot \mathrm{min}^{-1} \mathrm{He}$ purge) power compensation calorimeter. Temperature calibration was performed using indium, $T_{\text {fus }}=429.75 \mathrm{~K}$, and cyclohexane, $T_{\text {fus }}=(279.81 \pm 0.04) \mathrm{K}$, or cyclohexane, $T_{\text {fus }}=(279.81 \pm$ $0.04) \mathrm{K}, T_{\text {trs }}=(186.25 \pm 0.02) \mathrm{K}$, and cyclopentane, $T_{\text {trs }}=$ $(138.06 \pm 0.05) \mathrm{K}, T_{\text {fus }}=(179.72 \pm 0.05) \mathrm{K}$, depending on the temperature range studied. ${ }^{16}$ Indium, $\Delta_{\text {fus }} H=(3286 \pm$ 
Table 1. Molar Heat Capacity Values, $C_{p, m}$, for cis-1,2-Cyclohexanediol at Different Temperatures $T$

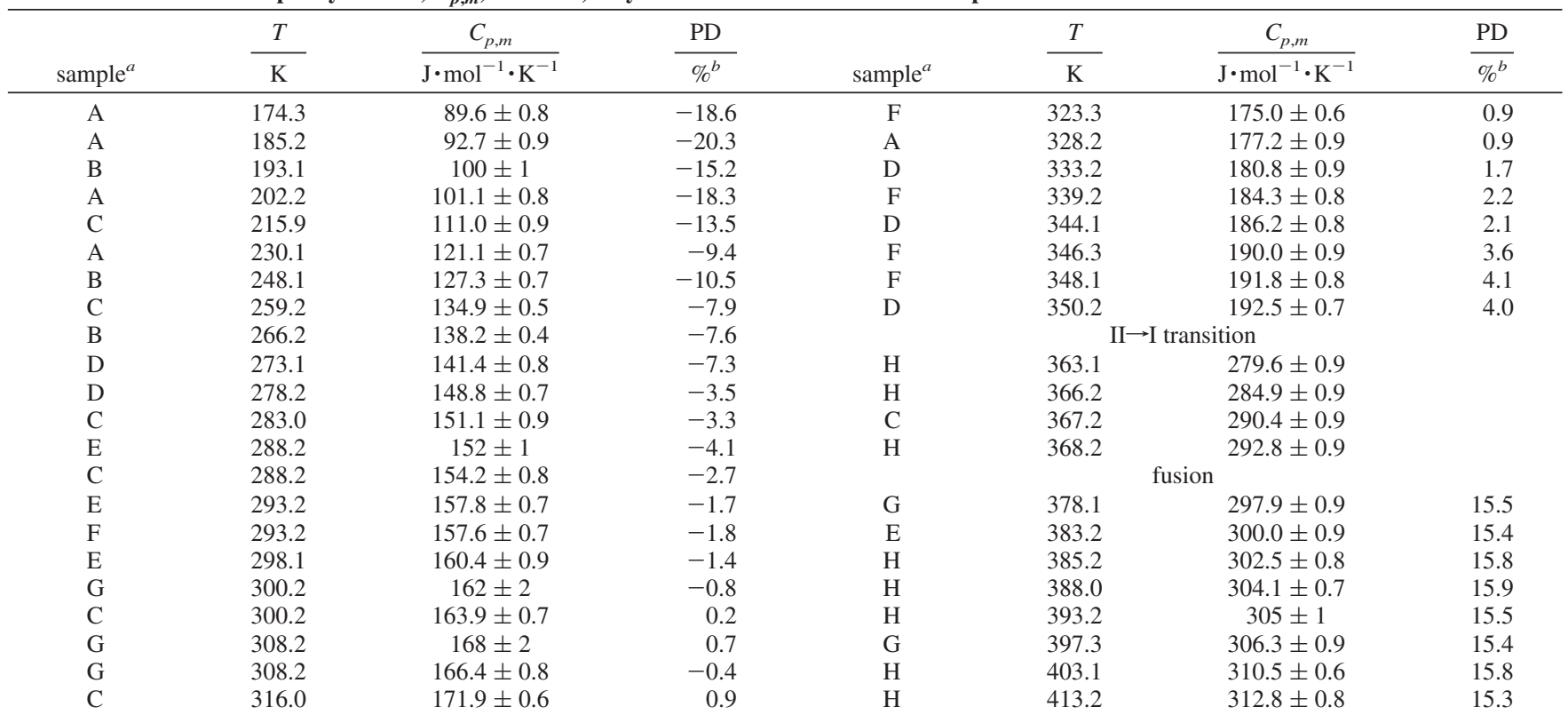

${ }^{a} \mathrm{~A}, 10.16 \mathrm{mg}$; B, $16.17 \mathrm{mg}$; C, $19.82 \mathrm{mg}$; D, $16.30 \mathrm{mg}$; E, $12.93 \mathrm{mg} ; \mathrm{F}, 19.24 \mathrm{mg} ; \mathrm{G}, 13.26 \mathrm{mg}$; H, $14.84 \mathrm{mg} .{ }^{b}$ Percent deviation, PD $=\left[\left(C_{p, m}-\right.\right.$ $\left.\left.C_{p, m}{ }^{\text {est }}\right) / C_{p, m}\right] . C_{p, m}$ is the experimental molar heat capacity value, and $C_{p, m}$ est is the estimated heat capacity using group contribution methods by Goodman et al. ${ }^{1}$ in the case of solids and Rûžička et al. ${ }^{3}$ in the case of liquids.

Table 2. Molar Heat Capacity Values, $C_{p, m}$, for $(1 R, 2 R)$-trans-Cyclohexanediol at Different Temperatures $T$

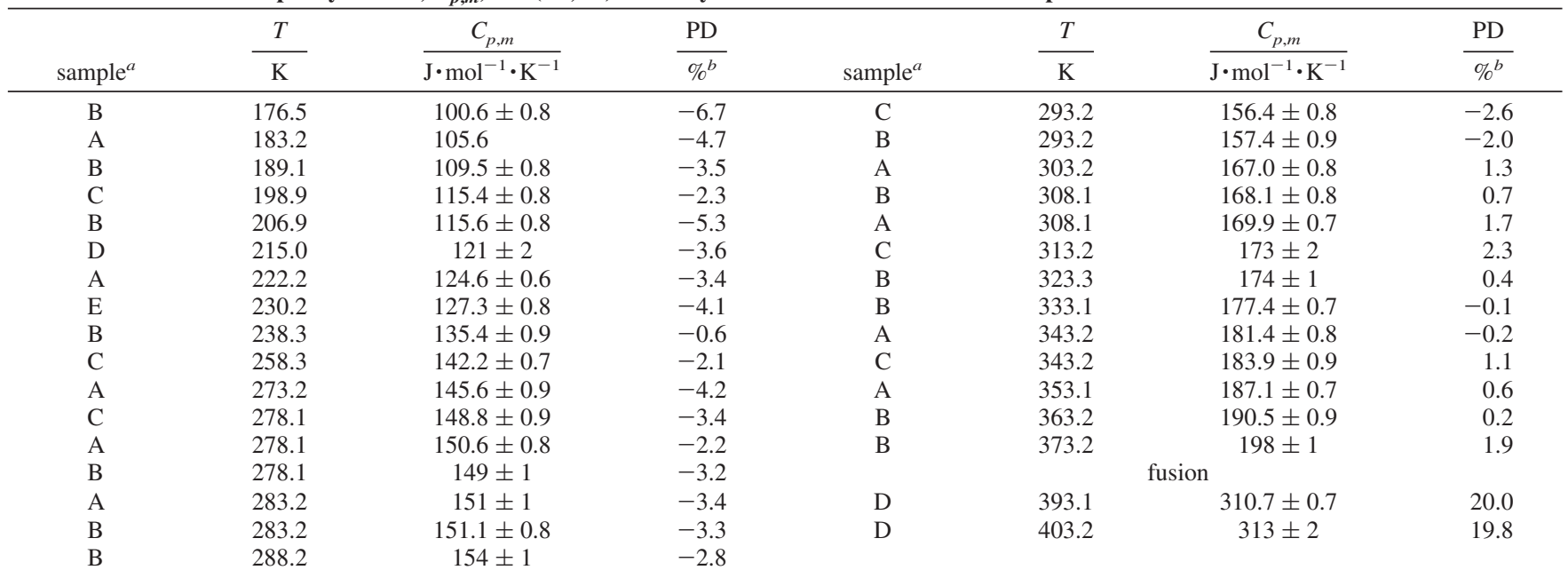

${ }^{a} \mathrm{~A}, 13.24 \mathrm{mg}$; B, $11.24 \mathrm{mg}$; C, $8.94 \mathrm{mg}$; D, $7.12 \mathrm{mg}$; E, $12.34 \mathrm{mg} .{ }^{b}$ Percent deviation, $\mathrm{PD}=\left[\left(C_{p, m}-C_{p, m}{ }^{\text {est }}\right) / C_{p, m}\right] . C_{p, m}$ is the experimental molar heat capacity value, and $C_{p, m}$ est is the estimated heat capacity using group contribution methods by Goodman et al. ${ }^{1}$ in the case of solids and Rûžička et $\mathrm{al}^{3}{ }^{3}$ in the case of liquids.

13) $\mathrm{J} \cdot \mathrm{mol}^{-1}$, or cyclohexane, $\Delta_{\text {trs }} H=(6713 \pm 74) \mathrm{J} \cdot \mathrm{mol}^{-1}$, were also used for enthalpy calibration. ${ }^{16}$ A standard deviation equal to $0.1 \mathrm{~K}$ is obtained for temperature.

Experimental Procedure. The methodology followed for heat capacity determination has been described as the enthalpic method. ${ }^{17-19}$ The calorimeter was stabilized at the initial temperature at least for $5 \mathrm{~min}$, and then the temperature was raised by $3 \mathrm{~K}$ at a scanning rate $\beta=2 \mathrm{~K} \cdot \mathrm{min}^{-1}$. As the final temperature was reached, a $5 \mathrm{~min}$ stabilization period was maintained. For each $C_{p, m}$ determination, three different experiments, using this temperature program, were performed. First of all, a baseline was run with empty pans and the calibration factor determined with an appropriate standard substance. The sample was then studied using the same temperature program. These operations, several runs for each, were always performed in the same day. The calculated $C_{p, m}$ values were assigned to the temperature corresponding to the mean of the scanned temperature range. Heat capacity calibration was made using synthetic sapphire, NIST-RM $720,{ }^{16,20,21}$ and benzoic acid, SRM LGC 2606, ${ }^{16,21,22}$ was used to verify the uncertainty of the experimental procedure. Uncertainty better than $1.5 \%$ was achieved.

Masses between $m=$ (7 and 20) $\mathrm{mg}$ were used in sealed Perkin-Elmer $40 \mu \mathrm{L}$ aluminum pans. The results presented at each temperature are the mean of at least three runs. Different samples for each substance under study were used to confirm the reliability of data. $C_{p, m}$ determinations at equal or adjacent temperatures were always performed on different days.

In this work, the uncertainties are expressed by one standard deviation. 
Table 3. Molar Heat Capacity Values, $C_{p, m}$, for $(1 S, 2 S)$-trans-Cyclohexanediol at Different Temperatures $T$

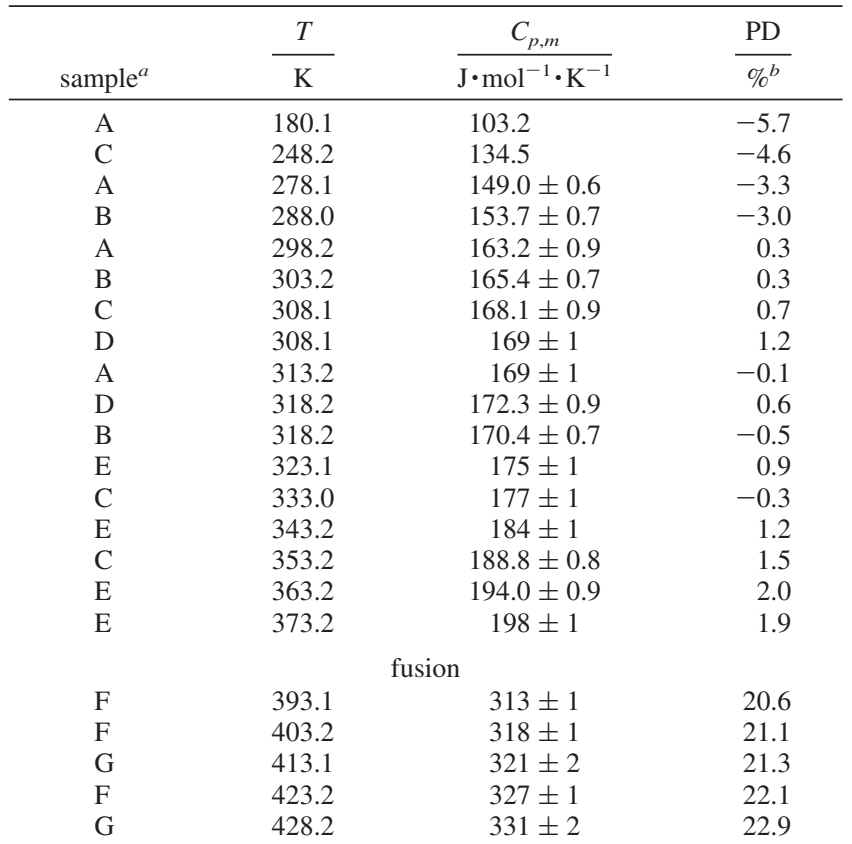

${ }^{a} \mathrm{~A}, 14.32 \mathrm{mg}$; B, $15.41 \mathrm{mg} ; \mathrm{C}, 2.67 \mathrm{mg}$; D, $11.01 \mathrm{mg}$; E, $12.74 \mathrm{mg}$; F, $8.18 \mathrm{mg} ; \mathrm{G}, 6.85 \mathrm{mg} .{ }^{b}$ Percent deviation, $\mathrm{PD}=\left[\left(C_{p, m}-C_{p, m}{ }_{\text {est }}\right) /\right.$ $\left.C_{p, m}\right] . C_{p, m}$ is the experimental molar heat capacity value, and $C_{p, m}$ est is the estimated heat capacity using group contribution methods by Goodman et al. ${ }^{1}$ in the case of solids and Rûžička et al. ${ }^{3}$ in the case of liquids.

\section{Results and Discussion}

In Table 1, the results obtained for the heat capacities of cis1,2-cyclohexanediol are given, and Tables 2 and 3 contain the results for the enantiomers of trans-1,2-cyclohexanediol. For better visualization, the values found for heat capacity are plotted against temperature in Figures 1 and 2.

The temperature dependence of the heat capacity of 1,2cyclohexanediol isomers both in the solid and in the liquid phases, in the range of temperatures considered, is well described by linear functions

$$
C_{p, m} /\left(\mathrm{J} \cdot \mathrm{mol}^{-1} \cdot \mathrm{K}^{-1}\right)=a+b(T / \mathrm{K})
$$

whose coefficients, $a$ and $b$, together with their respective standard deviations, determined by the least-squares method, are given in Table 4.

The $c$ is-isomer presents three phases on heating: a crystalline phase, stable below $T=360 \mathrm{~K}$, crystal II, an intermediate phase, crystal I, between $T=360 \mathrm{~K}$ and $T=372 \mathrm{~K}$, and the liquid phase for temperatures above $T=372 \mathrm{~K}^{.14,15}$ The transition between phases II and I $\left(T_{\text {trs }}=360.4 \mathrm{~K}, \Delta_{\text {trs }} H=19.9\right.$ $\left.\mathrm{kJ} \cdot \mathrm{mol}^{-1}\right)^{14}$ is accompanied by an increase in $C_{p, m}$ of about 80 $\mathrm{J} \cdot \mathrm{mol}^{-1} \cdot \mathrm{K}^{-1}$, while the transition between phase I and the liquid $\left(T_{\text {fus }}=371.6 \mathrm{~K}, \Delta_{\text {fus }} H=3.3 \mathrm{~kJ} \cdot \mathrm{mol}^{-1}\right)^{14}$ gives rise to the increase of $C_{p, m}$ of only $5 \mathrm{~J} \cdot \mathrm{mol}^{-1} \cdot \mathrm{K}^{-1}$. From these data, a clear conclusion may be drawn about phase $\mathrm{I}$ : it is evident that phase I has a highly disordered structure, not far from that of the liquid. A typical DSC curve obtained in heating runs at $\beta=2 \mathrm{~K} \cdot \mathrm{min}^{-1}$ is given as Supporting Information.

The enantiomers of the trans-isomer exhibit only one solid phase, stable for temperatures below $T=383 \mathrm{~K} \cdot{ }^{15,23}$ Fusion $\left(T_{\text {fus }}=382.6 \mathrm{~K}, \Delta_{\text {fus }} H=21.0 \mathrm{~kJ} \cdot \mathrm{mol}^{-1}\right)^{23}$ gives rise to an increase of $C_{p, m}$ of about $100 \mathrm{~J} \cdot \mathrm{mol}^{-1} \cdot \mathrm{K}^{-1}$. No significant differences between the pure enantiomers were observed, as

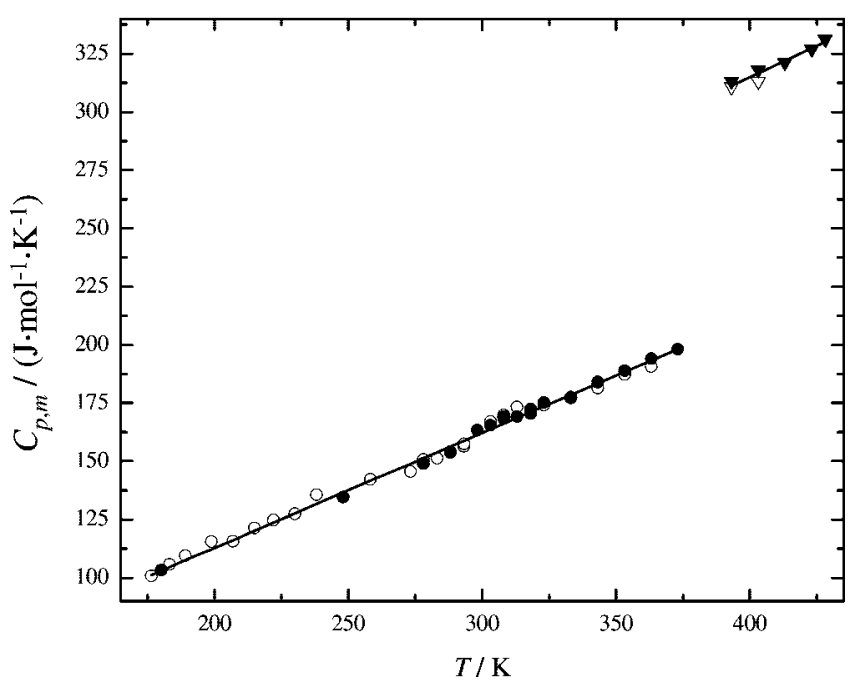

Figure 2. Molar heat capacity of the condensed phases of the enantiomers of trans-1,2-cyclohexanediol in the temperature range from $T=$ (176 to 428) K. $\bigcirc$, solid $(1 R, 2 R)$-trans-cyclohexanediol; $\bigcirc$, solid $(1 S, 2 S)$-transcyclohexanediol; $\nabla$, liquid $(1 R, 2 R)$-trans-cyclohexanediol; $\boldsymbol{\nabla}$, liquid $(1 S, 2 S)$ trans-cyclohexanediol.

Table 4. Parameters $a$ and $b$ of the Equation $C_{p, m} /\left(\mathrm{J} \cdot \mathrm{mol}^{-1} \cdot \mathrm{K}^{-1}\right)=$ $a+b(T / K)$

\begin{tabular}{llcc}
\hline & temp range/K & $a$ & $b$ \\
\hline cis-1,2-cyclohexanediol & 173 to 350 & $-17.6 \pm 1.9$ & $0.5964 \pm 0.0064$ \\
& 378 to 413 & $137 \pm 12$ & $0.426 \pm 0.032$ \\
trans-1,2-cyclohexanediol & 176 to 373 & $15.2 \pm 1.6$ & $0.4896 \pm 0.0056$ \\
$\begin{array}{l}\text { enantiomers } \\
\text { 393 to } 428\end{array}$ & $100 \pm 24$ & $0.537 \pm 0.059$
\end{tabular}

expected. A typical DSC curve obtained in heating runs at $\beta=$ $2 \mathrm{~K} \cdot \mathrm{min}^{-1}$ is given as Supporting Information.

To our knowledge, there is only one work dealing with the heat capacity of 1,2-cyclohexanediols. ${ }^{24}$ The measurements were made above room temperature, and the values reported for the trans-1,2-isomer concern the racemic mixture. The enantiomers and the racemic substance may have distinct thermodynamic properties in the solid phase, depending on the (solid + liquid) phase diagram of the enantiomer mixture. ${ }^{23,25}$ This is the case for trans-1,2-cyclohexanediol, so no comparison between our values and Cairong's will be carried out. Cairong and coworkers $^{24}$ report heat capacity values for cis-1,2-cyclohexanediol in the solid state for $T=(310$ to 355$) \mathrm{K}$ and in the liquid state for $T=(375$ to 470$) \mathrm{K}$. The values presented are systematically higher than those found in the present work. The differences are quite large, ranging in the solid from $45 \%$ at the lower temperature up to $100 \%$ for the higher temperature. For temperatures between $T=325 \mathrm{~K}$ and $T=355 \mathrm{~K}$, the values reported by Cairong et al. are higher than those of the liquid at $375 \mathrm{~K}$. In the liquid at $T=380 \mathrm{~K}$, our values and Cairong's are not significantly different, but at $T=413 \mathrm{~K}$, a divergence of about $34 \%$ is observed. It is worthy to note that the authors of ref 24 also did not detect the solid-solid phase transition in the cis-isomer.

The power law group contribution method developed by Goodman and co-workers ${ }^{1}$ for organic solids was applied to assess heat capacity values of the 1,2-cyclohexanediols. This method, which does not distinguish between isomers, uses the following equation to estimate $C_{p, m}$

$$
C_{p, m} /\left(\mathrm{J} \cdot \mathrm{mol}^{-1} \cdot \mathrm{K}^{-1}\right)=\frac{A}{1000}(T / \mathrm{K})^{0.79267}
$$

$A$ is given by 


$$
A=\exp \left(6.7796+\sum_{i}^{k} a_{i} n_{i}+\sum_{i}^{k} b_{i} n_{i}^{2}\right)
$$

$a_{i}$ and $b_{i}$ are parameters characteristic of group $i$, and $n_{i}$ is the number of each type of group making up the molecule. For 1,2-cyclohexanediol, the following equation is obtained

$$
C_{p, m} /\left(\mathrm{J} \cdot \mathrm{mol}^{-1} \cdot \mathrm{K}^{-1}\right)=\frac{1777.71}{1000}(T / \mathrm{K})^{0.79267}
$$

Deviations between experimental and calculated values are presented in Tables 1 to 3 . The predictions made by the Goodman method are quite satisfactory, with deviations ranging from ( -7 to 2$) \%$ for trans-1,2-cyclohexanediol and from ( -20 to 4$) \%$ in the case of the cis-isomer. The highest deviations are registered for cis-1,2-cyclohexanediol for temperature values below $250 \mathrm{~K}$. The crystalline structures of cis-1,2-cyclohexanediol and of $(1 S, 2 S)$-trans-cyclohexanediol were determined by X-ray diffraction and are different. The cis-isomer crystallizes in the orthorhombic Pbca space group ${ }^{26}$ and the trans-isomer in the hexagonal $P 3{ }_{1} 21 .{ }^{27}$ Consequently, it is not unexpected that they have different heat capacity values, and naturally, the Goodman method cannot predict with similar precision the heat capacity for both isomers.

The heat capacity of pure organic liquids, from the normal melting temperature to the normal boiling point, can be estimated by the Rûžička et al. ${ }^{2,3}$ group contribution method as follows

$$
\frac{C_{p, m}}{R}=\sum_{i}^{k} n_{i} \Delta c_{i}
$$

$n_{i}$ has the meaning given above, and $\Delta c_{i}$ is the dimensionless value of the contribution of group $i$ which the authors express as a function of temperature. For cis-1,2-cyclohexanediol, the following equation is obtained

$$
\begin{aligned}
\frac{C_{p, m}}{R}=-7.234046+0.1489962(T / \mathrm{K})- \\
1.31617 \cdot 10^{-4}(T / \mathrm{K})^{2}
\end{aligned}
$$

and for the trans-isomer

$$
\begin{gathered}
\frac{C_{p, m}}{R}=-9.68424+0.17200235(T / \mathrm{K})- \\
1.813786 \cdot 10^{-4}(T / \mathrm{K})^{2}
\end{gathered}
$$

The values obtained in the present work are higher than those estimated by the Rûžička method for both compounds, with the differences, presented in Tables 1 to 3, being of the order of 20 $\%$ for the trans-isomer and about $15 \%$ for the cis-one. In their work, Zabransky and Rûžička ${ }^{3}$ stress some problems in the prediction of heat capacity values for diols, namely, high uncertainty or inadequate temperature dependence.

\section{Concluding Remarks}

Heat capacity gives evidence for the structural differences accompanying the fusion process of 1,2-cyclohexanediol isomers. The fusion of the cis-isomer takes place in two steps, and a disordered solid phase resulting from the crystalline phase is obtained before the isotropic liquid. The $(1 R, 2 R)$ - and $(1 S, 2 S)$ enantiomers of the trans-isomer show a one-step fusion process.

Comparison of heat capacity group contribution predictions with experimental data shows that the Goodman et al. ${ }^{1}$ power law method for organic solids gives quite satisfactory results, except for the cis-isomer for temperatures below $250 \mathrm{~K}$, where deviations rise up to $-20 \%$, whereas the estimates resulting from the Rûžička et al. method for liquids are systematically lower by (15 to 20) \% than the results obtained in the present work.

\section{Supporting Information Available:}

Figures S1 and S2. This material is available free of charge via the Internet at http://pubs.acs.org.

\section{Literature Cited}

(1) Goodman, B. T.; Wilding, W. V.; Oscarson, J. L.; Rowley, R. L. Use of the DIPPR Database for Development of Quantitative StructureProperty Relationship Correlations: Heat Capacity of Solid Organic Compounds. J. Chem. Eng. Data 2004, 49, 24-31.

(2) Rûžička, V.; Domalski, E. S. Estimation of the Heat Capacity of Organic Liquids as a Function of Temperature Using Group Additivity. II. Compounds of Carbon, Hydrogen, Halogens, Nitrogen, Oxygen, and Sulfur. J. Phys. Chem. Ref. Data 1993, 22, 619-657.

(3) Zabransky, M.; Rûžička, V. Estimation of the Heat Capacity of Organic Liquids as a Function of Temperature Using Group Additivity: An Amendment. J. Phys. Chem. Ref. Data 2004, 33, 1071-1081.

(4) Maki, T.; Fukae, K.; Harasawa, H.; Ohishi, T.; Matsumura, Y.; Onomura, O. Selective Oxidation of 1,2-Diols by Electrochemical Method Using Organotin Compound and Bromine Ion as Mediators. Tetrahedron Lett. 1998, 39, 651-654.

(5) Petursson, S. Tin(II) Chloride Catalyzed Reactions of Diazodiphenylmethane with Vicinal Diols in an Aprotic Solvent. The Reactions with cis- and trans-1,2-cyclohexanediols and 1,2-propanediol. Carbohydr. Res. 2003, 338, 963-968.

(6) Funakoshi, K.; Sakai, K.; Hata, T.; Tamura, C. Rh(I)-Catalyzed Formation of Two Conformers due to Cis-1,2-Cyclohexanediol. Tetrahedron Lett. 1989, 30, 4849-4852.

(7) Ohfune, Y.; Nanba, K.; Takada, I.; Kan, T.; Horikawa, M.; Nakajima, T. Asymmetric Syntheses of 5- and 6-Membered Carbocyclic Analogs via an Intramolecular Strecker Synthesis. Chirality 1997, 9, 459-462.

(8) Kakuchi, T.; Narumi, A.; Kaga, H.; Yamachi, Y.; Obata, M.; Uesaka, T.; Yokota, K. Chirality Induction in Cyclocopolymerization. 14. Template Effect of 1,2-Cycloalkanediol in the Cyclocopolymerization of Bis(4-vinylbenzoate)s with Styrene. Macromolecules 2001, 34, 3843.

(9) Mendicuti, F.; Mattice, W. L. Intramolecular Excimer Formation in Polyesters from Terephthalic Acid and Cyclohexanediols with Different Stereochemical Compositions. Polymer 1992, 33, 4180-4183.

(10) Alexakis, A.; Mangeney, P. Chiral Acetals in Asymmetric Synthesis. Tetrahedron: Asymmetry 1990, 1, 477-511.

(11) Food and Drug Administration; FDA's Statement for the Development of New Stereoisomeric Drugs. Chirality, 1992, 4, 338-340.

(12) Agranat, I.; Caner, H.; Caldwell, A. Putting Chirality to Work: The Strategy of Chiral Switches. Nat. Rev. Drug Discovery 2002, 1, 753768.

(13) Williams, A. Opportunities for Chiral Agrochemicals. Pestic. Sci. 1996, 46, 3-9.

(14) Maria, T. M. R.; Costa, F. S.; Leitão, M. L. P.; Redinha, J. S. A Calorimetric Study of Phase Transitions for some Cyclohexanediols. Thermochim. Acta 1995, 269/270, 405-413.

(15) Leitão, M. L. P.; Castro, R. A. E.; Costa, F. S.; Redinha, J. S. Phase Transitions of 1,2-Cyclohexanediol Isomers Studied by Polarized Light Microscopy and Differential Thermal Analysis. Thermochim. Acta 2001, 278, 117-124.

(16) Sabbah, R.; Xu-Wu, A.; Chickos, J. S.; Leitão, M. L. P.; Roux, M. V.; Torres, L. A. Reference Materials for Calorimetry and Differential Thermal Analysis. Sabbah, R., Ed.; Special Issue, Thermochim. Acta 1999, 331, 93-204.

(17) Flynn, J. H. Thermodynamic Properties from Differential Scanning Calorimetry by Calorimetric Methods. Thermochim. Acta 1974, 8, 6981.

(18) Flynn, J. H. Analysis of DSC Results by Integration. Thermochim. Acta 1993, 217, 129-149.

(19) Mraw, S. C.; Naas, D. F. The Measurement of Accurate Heat Capacities by Differencial Scanning Calorimetry. Comparison of DSC Results on Pyrite (100 to $800 \mathrm{~K}$ ) with Literature Values from Precision Adiabatic Calorimetry. J. Chem. Thermodyn. 1979, 11, 567-584.

(20) Reshetnikov, M. A. Equation for the Enthalpy of Corundum Between 0 and 2200K. Russ. J. Phys. Chem. 1969, 43, 1254-1257.

(21) Della Gatta, G.; Richardson, M. J.; Sarge, S. M.; Stølen, S. Standards, Calibration, and Guidelines in Microcalorimetry. Part 2. Calibration Standards for Differential Scanning Calorimetry. Pure Appl. Chem. 2006, 78, 1455-1476. 
(22) Arvidsson, K.; Falk, B.; Sunner, S. A. Small Sample Low Temperature Adiabatic Heat Capacity Calorimeter with an Automatic Data Acquisition System. Chem. Scr. 1976, 10, 93-200.

(23) Leitão, M. L. P.; Eusébio, M. E. S.; Maria, T. M. R.; Redinha, J. S. (Solid + Liquid) Phase Diagram for Trans-1,2-cyclohexanediol Enantiomer Mixtures. J. Chem. Thermodyn. 2002, 34, 557-568.

(24) Cairong, Z.; Yadong, Z.; Denggao, J. Enthalpy and Heat Capacity Data for 1,2-Cyclohexanediol. Chin. J. Chem. Eng. 2003, 11, 598600.

(25) Jacques J.; Collet, A.; Wilen, S. H., Enantiomers, Racemates and Resolutions; Krieger Publishing Company: Malabar, 1994; Chap. 2.
(26) Sillanpää, R.; Leskela, M.; Hiltunen, L. Crystal and Molecular Structures of $( \pm)$ trans- and cis-1,2-Cyclohexanediols. Acta Chem. Scand. B 1984, 38, 249-254.

(27) Hanessian, S.; Gomtsyan, A.; Simard, M.; Roelens, S. Molecular Recognition and Self-Assembly by "Weak" Hydrogen Bonding: Unprecedented Supramolecular Helicate Structures from Diamine/Diol Motifs. J. Am. Chem. Soc. 1994, 116, 4495-4496.

Received for review January 17, 2008. Accepted March 26, 2008.

JE800047T 